\title{
PHACOTRABECULECTOMY WITH INTRAOCULAR LENS (IOL) IMPLANTATION IN PATIENTS WITH CO- EXISTING PSEUDOEXFOLIATIVE GLAUCOMA AND CATARACT
}

\author{
Arshi Nazir1, Ejaz Akbar², Syed Tariq Qureshi³, Anshulee Sood ${ }^{4}$, Tania Sadiq55, Syed Heena Kubravi 6
}

1Post Graduate, Department of Ophthalmology, Government Medical College, Srinagar.

${ }^{2}$ Associate Professor, Department of Ophthalmology, Government Medical College, Srinagar.

${ }^{3}$ Professor and HOD, Department of Ophthalmology, Government Medical College, Srinagar.

4 Post Graduate, Department of Ophthalmology, Government Medical College, Srinagar.

5 Post Graduate, Department of Ophthalmology, Government Medical College, Srinagar.

${ }_{6}^{6}$ Post Graduate, Department of Ophthalmology, Government Medical College, Srinagar.

ABSTRACT
PURPOSE
To evaluate the efficacy of phacotrabeculectomy with Intraocular Lens (IOL) implantation in patients with pseudoexfoliative
glaucoma.

\section{MATERIAL AND METHODS}

This study included 46 eyes of 46 patients diagnosed with pseudoexfoliative glaucoma and clinically significant cataract. All eyes underwent phacotrabeculectomy with intra ocular lens implantation. Efficacy was measured by evaluating the changes in mean intraocular pressure, mean logMar BCVA, drug number, bleb status and complications.

\section{RESULT}

Postoperative reduction of IOP was very satisfactory for the whole group. The mean pre-operative IOP \pm SD was $31.27 \pm 7.82$ $\mathrm{mmHg}$. After the procedure, the mean IOP decreased to a level of $14.05 \pm 4.22 \mathrm{mmHg}$ at first week and $13.68 \pm 9.27 \mathrm{mmHg}$ at $1 \mathrm{month}$. The mean IOP values at 3 months were $13.77 \pm 3.52$ and $14.12 \pm 3.19 \mathrm{mmHg}$ at 6 months. The mean IOP at final visit was $14.57 \pm 3.44$ $\mathrm{mmHg}$. The mean value of pre-operative logMAR BCVA was $0.98 \pm 45$. It improved to a mean value of logMAR BCVA $0.36 \pm 37$ at one month, $\log$ MAR BCVA $0.37 \pm 37$ at 6 months and $\log$ MAR BCVA $0.39 \pm 65$ at the final visit after one year.

\section{CONCLUSION}

Phacoemulsification, IOL implantation and trabeculectomy is an efficacious and safe procedure for treating eyes with co-existing pseudoexfoliation glaucoma and cataract.

\section{KEYWORDS}

Phacotrabeculectomy, Pseudoexfoliation Syndrome, Pseudoexfoliation Glaucoma.

HOW TO CITE THIS ARTICLE: Nazir A, Akbar E, Qureshi ST, et al. Phacotrabeculectomy with intraocular lens (IOL) implantation in patients with co-existing pseudoexfoliative glaucoma and cataract. J. Evolution Med. Dent. Sci. 2016;5(33):1799-1804,

DOI: $10.14260 /$ jemds/2016/424

\section{INTRODUCTION}

Glaucoma, is a leading cause of irreversible blindness throughout the world. WHO statistics 1997, indicate glaucoma accounts for $15 \%$ of total global blindness. Glaucoma refers to a group of diseases that have in common a characteristic optic neuropathy with associated visual field loss for which elevated intraocular pressure is one of the primary risk factors. ${ }^{(1)}$ Glaucoma has been classified by several systems. According to classification based on initial events, glaucoma has been classified as: (A) Open angle, (B) Angle closure, (C) Developmental and (D) Glaucomas associated with other ocular and systemic disorders.(2) Pseudoexfoliation syndrome belongs to the last group of above classification.

Pseudoexfoliation syndrome is defined as a discrete clinical entity characterized by synthesis and progressive accumulation of fine white granular material in many ocular tissues.

Financial or Other, Competing Interest: None.

Submission 24-03-2016, Peer Review 05-04-2016,

Acceptance 09-04-2016, Published 23-04-2016.

Corresponding Author:

Dr. Arshi Nazir,

House No. 173B, Govt. Housing Colony,

Sanatnagar,

Srinagar.

E-mail: arshi.nazir.3@gmail.com

DOI: $10.14260 /$ jemds/2016/424
The first description of this condition appeared in Scandinavian literature in 1917, when Lindbergh described flaky material at the pupillary border in some patients with glaucoma.(3) Throughout the anterior segment including the lens, iris, trabecular structures, conjunctiva, corneal endothelium, ciliary body and zonules the exfoliative material may be detected histopathologically.(4) It is overall the most common identifiable cause of glaucoma worldwide and in some countries accounts for the majority of glaucoma. (5) The reported mean age of pseudoexfoliation syndrome patients ranges from 69 to 75 . And most epidemiological surveys demonstrate an increasing prevalence with increasing age. Men and women are probably equally affected.(6) It leads to both open angle and angle closure glaucoma and has been causatively associated with cataract, lens dislocation and central retinal vein occlusion.

Eyes with pseudoexfoliation have a greater frequency of complications at the time of cataract extraction, such as zonular dialysis, capsular rupture and vitreous loss. Based on the identification of accumulations in orbital tissues, skin specimen and visceral organs, pseudoexfoliation syndrome appears to be a generalised disorder of the extracellular matrix.

Glaucoma occurs more commonly in eyes with pseudoexfoliation syndrome than in those without it. Elevated intraocular pressure with or without glaucomatous damage 
occurs in approximately $25 \%$ of persons with pseudoexfoliation syndrome or about 6 to 10 times the rate in eyes without pseudoexfoliation syndrome. Pseudoexfoliation glaucoma has more serious clinical course and worse prognosis than primary open angle glaucoma.(7) There is significantly higher frequency and severity of optic nerve damage at the time of diagnosis, worse visual field damage, poorer response to medications, more severe clinical course and more frequent necessity for surgical intervention. ${ }^{(8)}$

All patients with pseudoexfoliation syndrome and raised intraocular pressure should be treated even in presence of normal fields and discs, because if untreated a large percentage of cases will develop damage. Glaucoma associated with pseudoexfoliation syndrome is basically treated on same lines as chronic open angle glaucoma, although it responds less well to medical therapy than does primary open angle glaucoma.(9) When conventional surgical intervention becomes necessary, filtering surgery is generally advocated.(10) In the new millennium of rapid advancements and modifications in all fields of science and technology, the treatment of coexisting cataract and glaucoma by combined procedure (Cataract extraction, intraocular lens implantation and trabeculectomy) has produced favourable results. Combined procedure not only improves Visual Acuity (VA) and control of Intraocular Pressure (IOP), but also decreases post-operative pressure spikes.(11)

\section{MATERIAL AND METHODS}

This was an observational case series carried out in the Department of Ophthalmology, Government Medical College, Srinagar, Jammu and Kashmir, India; 46 eyes of 46 patients diagnosed with pseudoexfoliation glaucoma and clinically significant cataract were taken up for this study. Studied subjects included 32 males and 14 females. Patients with exfoliation syndrome and cataract were included in this study if they had no associated ocular disease, previous surgery or trauma. Pre-operative assessment included detailed examination including Best Corrected Visual Acuity (BCVA) (Snellen's test types), which was later converted to logMAR values, slit-lamp biomicroscopy for presence of exfoliative material and cataract, intraocular pressure using Goldmann applanation tonometry, gonioscopy, detailed fundus examination for cup-disc ratio and other changes on the disc and A - Scan biometry. Selected cases also underwent visual field analysis depending on the maturity of cataract. Indications for trabeculectomy were uncontrolled IOP despite maximum tolerated medication and disease progression.

\section{PROCEDURE}

Consent for surgery was duly obtained from the patient or close relative of the patient. Pre-operative IOP was expressed as value measured at the visit immediately prior to the surgery. All surgeries were performed under peribulbar anaesthesia using $2 \%$ lidocaine. A single site was used for phacoemulsification and trabeculectomy. Limbal conjunctival peritomy performed at the 12 o'clock and a fornix based conjunctival flap was fashioned. Two millimetres posterior to the limbus at 12 o'clock position, a partial-thickness tangential scleral incision was made for 2.5 to $3 \mathrm{~mm}$. Then with a $2.6 \mathrm{~mm}$ Crescent knife a half-thickness scleral tunnel, which extended $1 \mathrm{~mm}$ into clear cornea was dissected. No antimetabolite was applied. Two limbal paracentesis were made at 10 and 2 o'clock positions. Anterior chamber was entered with $2.6 \mathrm{~mm}$ Keratome and anterior chamber was filled by methylcellulose and then a $5 \mathrm{~mm}$ anterior continuous curvilinear capsulorrhexis was performed. The nucleus was removed by phacoemulsification using the chop technique and a soft acrylic intraocular lens was placed in the bag.

Corneoscleral block excision was performed by Kelly punch. A peripheral iridectomy was performed, anterior chamber was reformed. The scleral incision was sutured and watertight suturing of the conjunctiva was performed by two 10-0 nylon. Post-operatively, after $24 \mathrm{hrs}$. patients were put on antibiotic steroid eye drops every 2 hours and then tapered gradually over following 4-6 weeks. Post-operative followup was done on first post-operative day, first post-operative week, first month and then after 3 months, 6 months and one year post-operatively. Followup assessment included BCVA, IOP, slit lamp examination for status and type of bleb, fundus examination and field of vision. Patients having post-operative IOP $>21 \mathrm{mmHg}$ were put on medical treatment and followed up.

\section{PROCEDURE}

Consent for surgery was duly obtained from the patient or close relative of the patient. Pre-operative IOP was expressed as value measured at the visit immediately prior to the surgery. All surgeries were performed under peribulbar anaesthesia using 2\% lidocaine. A single site was used for phacoemulsification and trabeculectomy. Limbal conjunctival peritomy performed at the 12 o'clock and a fornix-based conjunctival flap was fashioned. Two millimetres posterior to the limbus at 12 o'clock position, a partial-thickness tangential scleral incision was made for 2.5 to $3 \mathrm{~mm}$. Then with a $2.6 \mathrm{~mm}$ crescent knife, a half-thickness scleral tunnel which extended $1 \mathrm{~mm}$ into clear cornea was dissected. No antimetabolite was applied. Two limbal paracentesis were made at 10 and 2 o'clock positions. Anterior chamber was entered with $2.6 \mathrm{~mm}$ Keratome and anterior chamber was filled by methylcellulose and then a $5 \mathrm{~mm}$ anterior continuous curvilinear capsulorrhexis was performed.

The nucleus was removed by phacoemulsification using the chop technique and a soft acrylic intraocular lens was placed in the bag. Corneoscleral block excision was performed by Kelly punch. A peripheral iridectomy was performed, anterior chamber was reformed. The scleral incision was sutured and watertight suturing of the conjunctiva was performed by two 10-0 nylon. Post-operatively, after $24 \mathrm{hrs}$. patients were put on antibiotic steroid eye drops every 2 hours and then tapered gradually over following 4-6 weeks. Postoperative followup was done on first post-operative day, first post-operative week, first month and then after 3 months, 6 months and one year post-operatively. Followup assessment included BCVA, IOP, slit lamp examination for status and type of bleb, fundus examination and field of vision. Patients having post-operative IOP $>21 \mathrm{mmHg}$ were put on medical treatment and followed up.

\section{STATISTICS}

Statistical software SPSS 16.0 was used to carry out the statistical analysis of data. Data was analysed by means of descriptive statistics, viz. means, standard deviations and percentages and presented by Bar diagrams. Paired ' $t$ ' test was 
employed for comparing preoperative IOP with postoperative IOP. A p value of $<0.05$ was considered statistically significant.

\section{RESULTS AND OBSERVATIONS}

\section{Baseline Data}

Our study included 46 eyes of 46 patients diagnosed with pseudoexfoliation glaucoma with clinically significant cataract. Mean age and standard deviation of studied subjects was $66.2 \pm 8.8$ years. The distribution was not statistically significant (Table 1); $32(69.5 \%)$ of studied subjects were males and 14 (30.5\%) were females (Table 2). Right eye was operated in $24(53.5 \%)$ patients and left eye was operated in $22(47.5 \%)$ patients (Table 3). Exfoliation material was present on the pupillary border in $78 \%$ cases, while as $38 \%$ had exfoliation material present on anterior lens capsule at the time of diagnosis (Table 4). More than one site was involved at the time of diagnosis in majority of patients. Pre-operative CD ratio was in the range of $0.3-0.5$ in $30 \%$ of cases, $0.6-0.8$ in $46 \%$ cases and 0.9 in $24 \%$ cases (Table 4 ).

\section{Intraocular Pressure}

Preoperative IOP was taken as IOP of the patient one day prior to the surgery whether on medical treatment or not. Almost all patients 44 (95.5\%) were on medical treatment before trabeculectomy, except $2(4.5 \%)$ patients in whom primary trabeculectomy was done. Pre-operatively 18 (40\%) cases were in the range of $21-30 \mathrm{mmHg}$ on medical treatment, 11 (24\%) cases were in the range of $>15-20 \mathrm{mmHg}$, who though medically controlled had to undergo trabeculectomy either due to progressive loss of visual field or intolerance to medical therapy and $13(28 \%)$ cases were in preoperative IOP range of 31-40 mmHg. Also 2 (6\%) cases had IOP in the range of 41-50 $\mathrm{mmHg}$ and 1 case (2\%) had pre-operative IOP of $60 \mathrm{mmHg}$.

The mean pre-operative IOP \pm SD was $31.27 \pm 7.82 \mathrm{mmHg}$. After the phacotrabeculectomy with IOL implantation was performed the mean IOP decreased to a level of $14.05 \pm 4.22$ $\mathrm{mmHg}$ at first post-operative week and $13.68 \pm 9.27 \mathrm{mmHg}$ at first post-operative month. The mean IOP value at 3 months was $13.77 \pm 3.52 \mathrm{mmHg}$, while as at 6 months the mean value was $14.12 \pm 3.19 \mathrm{mmHg}$.

The mean IOP at final visit was $14.57 \pm 3.44 \mathrm{mmHg}$. The changes were statistically significant $(\mathrm{p}<0.001)$ (Table 6) (Fig. 1). Post-operative reduction of IOP was very satisfactory for the whole group with about 39 patients (85\%) having a postoperative IOP of 10-20 mmHg in first week. Moreover 4 (9\%) patients had post-operative IOP of less than $10 \mathrm{mmHg}$ making the total percentage of controlled cases as $94 \%$ in first week. However, in overall followup, 5 cases showed unsatisfactory post-operative IOP reduction. Three amongst them showed controlled IOP on postoperative medical treatment and 2 maintained a post-operative IOP $>25 \mathrm{mmHg}$, despite continuation of medical treatment.

The mean pre-operative anti-glaucoma drug number was $3.09 \pm 2$. It was significantly reduced to a mean value of $0.31 \pm 7$ at 6 months and $0.38 \pm 3$ at 1 year $(\mathrm{p}<0.001)$ (Table 7$)$ (Fig. 2).

At the end of first week blebs were formed in 43 cases, out of which $31(67 \%)$ were flat diffuse type, while as 12 (26\%) were thin polycystic type. Remaining 3 (7\%) cases showed no bleb.
At final visit post-operative cup-disc ratio remained same in 39 (85\%) cases and deteriorated in 7 (15\%) cases. However, none of the cases showed any improvement.

\section{Best Corrected Visual Acuity (BCVA)}

The mean value of pre-operative logMAR BCVA was $0.98 \pm 45$. After phacotrabeculectomy the value improved to a mean of logMAR BCVA $0.36 \pm 37$ at one month, logMAR BCVA $0.37 \pm 37$ at 6 months and logMAR BCVA $0.39 \pm 65$ at the final visit after one year (Table 8) (Fig. 3). Thus showing an overall improvement in BCVA by $62 \%$ at 6 months and $60.2 \%$ at one year. The difference was statistically significant $(\mathrm{P}<0.001)$.

\section{COMPLICATIONS}

Intraoperative complications include poor pupillary dilatation in $9(20 \%)$ of cases and gross subluxation of the lens with implantation of anterior chamber intraocular lens in $1(2 \%)$ case. Early post-operative complications included shallow anterior chamber in $5(10 \%)$ cases, fibrin exudation and pupillary membrane formation in $4(8 \%)$ cases, flat anterior chamber in $2(4 \%)$ cases and hyphema in $2(4 \%)$ of cases. Most common late post-operative complication included posterior capsular opacification seen in 14 (32\%) of cases. Additional surgical procedures included anterior chamber reformation in $3(7 \%)$ of cases and conjunctival resuturing in $2(4 \%)$ cases (Table 9).

\begin{tabular}{|c|c|c|}
\hline Age in Years & No. of Patients & \% Age \\
\hline$<60$ & 7 & $16 \%$ \\
\hline $60-70$ & 26 & $56 \%$ \\
\hline$>70$ & 13 & $28 \%$ \\
\hline \multicolumn{2}{|c|}{ Mean Age: 66.2 \pm 8.8 Years } \\
\hline \multicolumn{2}{|c|}{ Table 1: Age Distribution of Studied Subjects } \\
\hline
\end{tabular}

\begin{tabular}{|c|c|c|}
\hline Gender & No. of Patients & \% Age \\
\hline Male & 32 & $69.5 \%$ \\
\hline Female & 14 & $30.5 \%$ \\
\hline Total & $\mathbf{4 6}$ & $\mathbf{1 0 0 \%}$ \\
\hline Table 2: Gender Distribution of Studied Subjects \\
\hline
\end{tabular}

\begin{tabular}{|c|c|c|}
\hline & No. of Patients & \% Age \\
\hline Right Eye & 24 & $53.5 \%$ \\
\hline Left Eye & 22 & $47.5 \%$ \\
\hline Total & 46 & $100 \%$ \\
\hline \multicolumn{3}{|c|}{ Table 3: Eye Operated } \\
\hline
\end{tabular}

\begin{tabular}{|c|c|c|}
\hline & $\begin{array}{c}\text { No. of } \\
\text { Patients }\end{array}$ & \% Age \\
\hline $\begin{array}{c}\text { Exfoliation Material on Pupillary } \\
\text { Border }\end{array}$ & 36 & $78 \%$ \\
\hline $\begin{array}{c}\text { Exfoliation Material on Anterior } \\
\text { Lens Capsule }\end{array}$ & 18 & $38 \%$ \\
\hline $\begin{array}{c}\text { Exfoliation Material in Angle with } \\
\text { Pigmentation }\end{array}$ & 8 & $16 \%$ \\
\hline $\begin{array}{c}\text { Exfoliation Material on Corneal } \\
\text { Endothelium }\end{array}$ & 8 & $16 \%$ \\
\hline More than one site was Involved in Majority of Patients \\
\hline \multicolumn{2}{|c|}{ Table 4: Pre-Operative Type of Exfoliation } \\
as per SLE and Gonioscopy
\end{tabular}




\begin{tabular}{|c|c|c|}
\hline & No. of Patients & \% Age \\
\hline $0.3-0.5$ & 14 & $30 \%$ \\
\hline $0.6-0.8$ & 22 & $46 \%$ \\
\hline 0.9 & 10 & $24 \%$ \\
\hline \multicolumn{2}{|c|}{ Table 5: Pre-Operative CD Ratio } \\
\hline
\end{tabular}

\begin{tabular}{|c|c|c|}
\hline & Mean IOP (mmHg) & SD \\
\hline Baseline & 31.27 & 7.82 \\
\hline First Post-operative Week & 14.05 & 4.22 \\
\hline One Month & 13.68 & 9.27 \\
\hline Three Months & 13.77 & 3.52 \\
\hline Six Months & 14.12 & 3.19 \\
\hline One Year & 14.57 & 3.44 \\
\hline Table 6: Changes in Intraocular Pressure \\
over the Studied Period \\
\hline
\end{tabular}

\begin{tabular}{|c|c|c|}
\hline & Mean & SD \\
\hline Pre-Operative Drug Number & 3.09 & 2 \\
\hline Drug Number at 6 Months & 0.31 & 7 \\
\hline Drug Number at One Year & 0.38 & 3 \\
\hline Table 7: Drug Number of Anti-Glaucoma Medication \\
\hline
\end{tabular}

\begin{tabular}{|c|c|c|}
\hline & Mean & SD \\
\hline Baseline BCVA & 0.98 & 45 \\
\hline BCVA at one Month & 0.36 & 35 \\
\hline BCVA at 6 Months & 0.37 & 37 \\
\hline BCVA at One Year & 0.39 & 65 \\
\hline Table 8: Changes in LogMAR BCVA over Studied Period \\
\hline
\end{tabular}

\begin{tabular}{|c|c|c|}
\hline & Number & \% Age \\
\hline Poor Pupillary Dilation & 9 & $20 \%$ \\
\hline Gross Subluxation of Lens & 1 & $2 \%$ \\
\hline Shallow Anterior Chamber & 5 & $10 \%$ \\
\hline $\begin{array}{c}\text { Fibrin Exudation and Pupillary } \\
\text { Membrane Formation }\end{array}$ & 4 & $8 \%$ \\
\hline Flat Anterior Chamber & 2 & $4 \%$ \\
\hline Hyphema & 2 & $4 \%$ \\
\hline Posterior Capsular Opacification & 14 & $32 \%$ \\
\hline \multicolumn{3}{|c|}{ Table 9: Complications over the Studied Period } \\
\hline
\end{tabular}

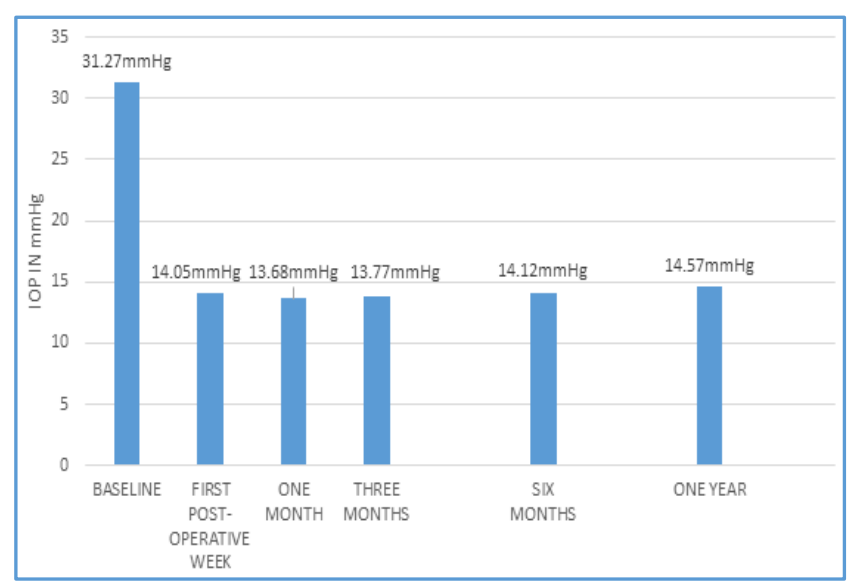

Fig. 1: A Demonstration of Changes in the Mean Intraocular Pressure over the Studied Period of Time. Note that a Statistically Significant Decrease has been observed in the IOP from a Mean Baseline IOP of $31.27 \mathrm{mmHg}$ to IOP of $14.2 \mathrm{mmHg}$ at the final visit.

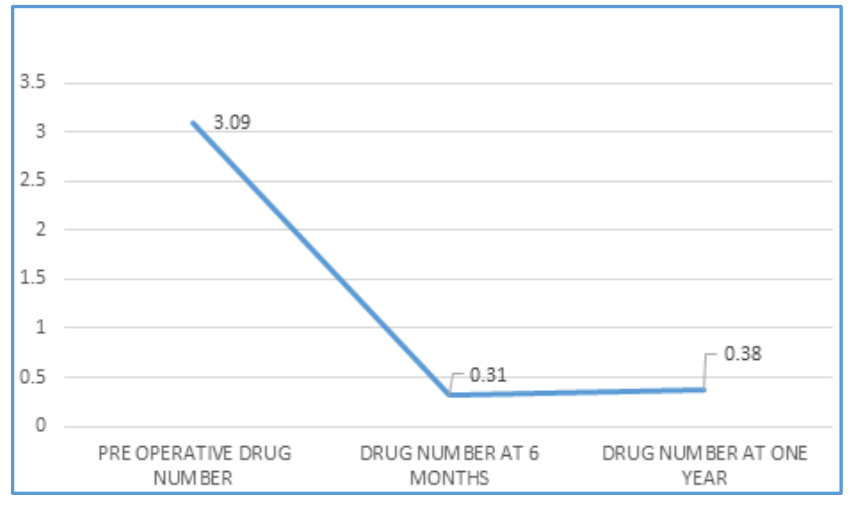

Fig. 2: Demonstrating a Statistically Significant Decrease in the Drug Number from 3.09 Preoperatively, to 0.31 at a Follow-Up Period of 6 months and 0.38 at the Final Visit

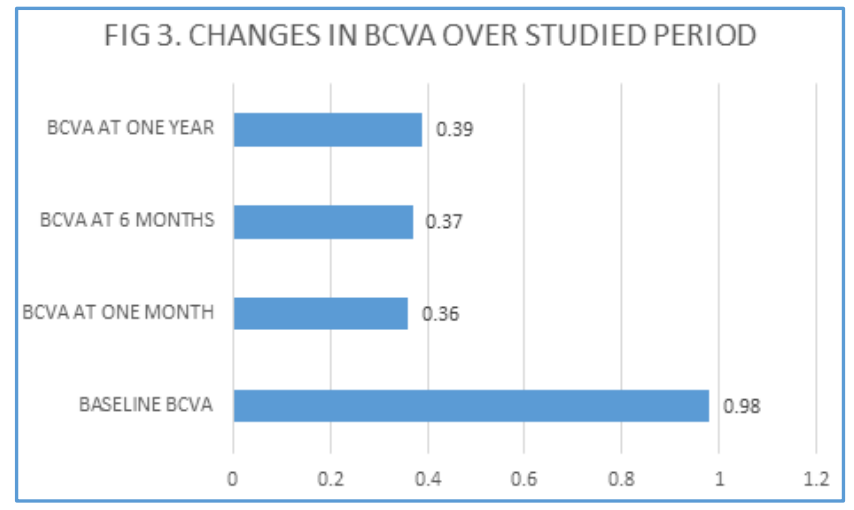

Fig. 3: Demonstrating the Improvement in logMAR BCVA where the BCVA Improves from Baseline Value of 0.98 to $0.37,0.36$ and 0.39 at one month, three months and one year respectively

\section{DISCUSSION}

Ophthalmologists have been facing the challenge of simultaneous management of cataract and glaucoma in our elderly population with pseudoexfoliation syndrome. The surgical management of coexisting glaucoma and cataract has changed a lot, raising critical management issues.(12) The benefits of combined procedure include to avoid temporary increase in intraocular pressure in the initial postoperative period and to achieve long-term improvement in IOP control with one surgical procedure, while removing the visual impairment and save the patient one surgery.(13) Although the optimal surgical approach for cataract patients with coexisting glaucoma is still under evolution, phacotrabeculectomy may be considered as the current standard option.

The pseudoexfoliation syndrome usually affects the elderly and steady increase in prevalence occurs with advancing age.(3) Our study also supports this, as the mean age of the patients was $66.2 \pm 8.8$ years. Various studies have demonstrated that the clinical course in pseudoexfoliative glaucoma is likely to be more serious as compared with primary open angle glaucoma. Level of IOP, progression of visual defects and glaucomatous optic neuropathy are more pronounced in exfoliative glaucoma.(14) Moreover, pseudoexfoliative eyes respond less readily to medical therapy, so that many of these require early surgery. Jacobi reported that after combined procedure in eyes with exfoliation syndrome, the mean IOP of $32.5 \mathrm{mmHg}$ with a mean 
of 2.1 antiglaucoma medications was decreased to the mean IOP of $18.1 \mathrm{mmHg}$ with a mean of 0.2 antiglaucoma medications after 6 months.(15) The mean pre-operative $\mathrm{IOP} \pm \mathrm{SD}$ in our study significantly decreased from a value of $31.27 \pm 7.82 \mathrm{mmHg}$ at baseline and $14.57 \pm 3.44 \mathrm{mmHg}$ at final visit, thereby showing an overall decrease by $16.7 \mathrm{mmHg}$ (53.40\%). Our results were comparable with Shingleton BJ et al.(16) and L J Katz et al.(17) The mean pre-operative antiglaucoma medication number in our study was $3.09 \pm 2$ and was reduced to a mean value of $0.31 \pm 7$ at 6 months and $0.38 \pm 3$ at 1 year. Our results were similar to Eslami et al.(18) and comparable with other studies.(16)(17)

Combining the two surgeries not only enhances the vision of the patients, but also provides independence from multiple glaucoma drugs and frequent follow ups, thus improving the quality of life.(19) The mean value of preoperative $\log M A R$ BCVA was 0.98 . It improved to a mean value of logMAR BCVA 0.35 at one month, a mean value of logMAR BCVA 0.37 at 6 months and a mean value of logMAR BCVA 0.39 at one year. The difference was statistically significant $(p<0.001)$. Our findings are in agreement with studies done by L J Katz et al.(17) and Eslami et al.(18)

Poor pupillary dilation is a well-known feature of pseudoexfoliation syndrome and can seriously hamper the surgeon's view. Phacoemulsification performed in patients with glaucoma is frequently challenging because of a number of factors including a small pupil that is resistant to pharmacologic dilation or even viscoelastic mechanical dilation.(19) In our study, 10 (20\%) patients presented with poor pupillary dilation. Local production and deposition of exfoliative material may lead to characteristic clinical and ultrastructural changes, which actively involve all structures of the anterior segment of the eye. These alterations may cause complication after surgical procedures. Many reports have mentioned increased rate of intraoperative complications that is, zonular dialysis, posterior capsular tear and vitreous loss. In our study, gross subluxation of the lens was encountered in $1(2 \%)$ cases.

A number of studies have presented evidence of dysfunction of the blood aqueous barrier in pseudoexfoliation syndrome with consecutive increase of aqueous flare and protein. Clinical response of inflammatory reaction and fibrin formation in eyes with pseudoexfoliation following cataract extraction appears to be related to these ultrastructural changes.(20) Fibrin exudation and pupillary membrane formation was encountered in $4(8 \%)$ patients in our study. The explanation elucidated for this is that the maintenance of a relatively controlled IOP during phacoemulsification incites less chamber reaction. Prior studies by Tezel et al.(21) and Wishart et al.(22) that have compared ECCE trabeculectomy with phacotrabeculectomy also documented lesser anterior chamber inflammatory reaction in phacotrabeculectomy group.

Most common late post-operative complication included posterior capsular opacification seen in $32 \%$ of cases.

\section{CONCLUSION}

Trabeculectomy combined with phacoemulsification is considered a safe, effective and economical strategy in the management of cataract associated with pseudoexfoliative glaucoma. It prevents early IOP spikes responsible for visual field wipeout in advanced glaucoma and provides visual rehabilitation with long-term IOP control. Also both the diseases are controlled in a single sitting, thus it eliminates the need for glaucoma medications and frequent follow-ups. This reduced incidence of complications and has made this surgery technically faster and superior. Other advantages include less induced astigmatism, early visual rehabilitation, reduced stimuli to wound healing, inflammation and postoperative bleb scarring and thus improving long-term filtration. The results obtained were promising; however, they do not permit us to draw definitive conclusions and further studies involving a larger number of patients are needed to confirm these results.

\section{REFERENCES}

1. Bruce Shields M. Textbook of glaucoma. Chap 1, 4th edn:page 1.

2. Bruce Shields M. Textbook of glaucoma. Chap 8, $4^{\text {th }}$ edn:page 147.

3. Naumann GO, Schloterz-Schrehardt U, Kuchle M. Pseudoexfoliation syndrome for the comprehensive ophthalmologist: intraocular and systemic manifestations. Ophthalmology 1998;105(6):951-68.

4. Prince AM, Ritch R. Clinical signs of the pseudoexfoliation syndrome. Ophthalmology 1986;93(6):803-7.

5. Ritch R. Exfoliation syndrome: the most common identifiable cause of open-angle glaucoma. J Glaucoma 1994;3(2):176-7.

6. Aasved H. The geographical distribution of fibrillopathia epitheliocapsularis, so-called senile exfoliation or pseudoexfoliation of the anterior lens capsule. Acta Ophthalmol (Copenh) 1969;47(3):792-810.

7. Layden WE, Shaffer RN. Exfoliation syndrome. Am J Ophthalmol 1974;78(5):835-41.

8. Tarkkanen A. Treatment of chronic open angle glaucoma associated with pseudoexfoliation. Acta Ophthalmol 1965;43(4):514-23.

9. Konstas AG, Jay JL, Marshall GE, et al. Prevelance, diagnostic features and response to trabeculectomy in exfoliation glaucoma. Ophthalmology 1993;100(5):61927.

10. Popovic V, Sjostrand J. Course of exfoliation and simplex glaucoma after primary trabeculectomy. Br J Ophthalmol 1999;83:305-10.

11. Rosdahl JA, Chen TC. Combined cataract and glaucoma surgeries: traditional and new combinations. Int Ophthalmol Clin 2010;50(1):95-106.

12. Monezo JL, Malonado MJ, Munoz G, et al. Combined procedure for glaucoma and cataract. A retrospective study. J cataract Refract Surg 1994;20(5):498-503.

13. Simmons ST, Litoff D, Nichols DA, et al. Extracapsular cataract extraction and posterior chamber intraocular lens implantation combined with trabeculectomy in patients with glaucoma. Am J Ophthalmol 1987;104(5):465-70.

14. Brooks AMV, Gillis WE. The presentation and prognosis of glaucoma in pseudoexfoliation of the lens capsule. Ophthalmology 1988;95(2):271-6.

15. Jacobi PC, Dietlein TS, Krieglstein GK. Comparative study of trabecular aspiration Vs trabeculectomy in glaucoma triple procedure to treat pseudoexfoliation glaucoma. Arch Ophthalmol 1999;117(10):1311-8. 
16. Shingleton BJ, Wooler KB, Bourne CI, et al. Combined cataract and trabeculectomy surgery in eyes with pseudoexfoliation glaucoma. J Cataract Refract Surg 2011;37(11):1961-70.

17. Jay Katz L, Camila Zangalli, Raymond Clifford, et al. The effect of pupil enlargement on surgical outcomes (an American ophthalmological society thesis). Trans Am Ophthalmol Soc 2013;111:155-68.

18. Yadollah Eslami, Massood Mohammadi, Ghasem Fakhraie, et al. Evaluation of the outcomes of one-site combined phacotrabeculectomy using sutureless tunnel technique without peripheral iridectomy in open angle glaucoma patients. Iranian Journal of Ophthalmology 2014;26(3):150-4.

19. Gosiengfiao DH, Latina MA. Avoiding complications in combined phacotrabeculectomy. Semin Ophthalmol 2002;17(3-4):138-43.
20. Walinder PE, Olivius EO, Nordell SI, et al. Fibrinoid reaction after extracapsular cataract extraction and relationship to exfoliation syndrome. J Cataract Refract Surg 1989;15(5):526-30.

21. Tezel G, Kolker AE, Kass MA, et al. Comparative results of combined procedures for glaucoma and cataract: I. Extracapsular cataract extraction versus phacoemulsification and foldable versus rigid intraocular lenses. Ophthalmic Surg Lasers 1997;28(7):539-50.

22. Wishart PK, Austin MW. Combined cataract extraction and trabeculectomy: phacoemulsification compared with extracapsular technique. Ophthalmic Surg 1993;24(12):814-21. 